\title{
Growth of Ag-Nanoparticles: Shape-Directing Role of Silver lons and Stabilizer in Aqueous Solutions
}

\section{Zoya Zaheer, Rafiuddin*}

*Nanoscience Research Laboratory, Department of Chemistry, Aligarh Muslim University, Aligarh 202002 , UP, India

*Author for corresponding. E-mail address: zoya.zaheer@gmail.com (Z. Zaheer).

\section{Abstract}

Silver nanoparticles were synthesized using Tulsi leaves extract as reducing as well as a capping agent to reduce the steps and parameters involved in the synthesis. The morphology, stability and optical properties of Ag-nanoparticles depend on reactants and stabilizer, cetyltrimethylammonium bromide (CTAB) concentrations. The silver nanoparticles were characterized by UV-visible spectrophotometer, and transmission electron microscope (TEM). Spherical morphology of the silver nanoparticles with an average diameter of $25 \mathrm{~nm}$. Morphology changed markedly from spherical aggregated to highly polydispersed in presence of CTAB.

Keywords: Silver nanoparticles; Extracellular; Morphology; CTAB

\section{Council for Innovative Research}

Peer Review Research Publishing System

\section{Journal: Journal of Advances in Chemistry}

Vol. 6, No. 3

editor@cirworld.com

www.cirworld.com, member.cirworld.com 


\section{Introduction}

Synthesis of noble metal nanoparticles has attracted immense attention for applications such as catalysis, electronics, optics, environmental, biosensors, biotechnology and in a new generation by using greener reducing agents is an area of constant interest from last two decades [1-10]. The general philosophy to the synthesis of advance metal nanoparticles from its salt solution is based on using a reducing agent in presence of a suitable stabilizing-, and capping-agent [11-13] Large number of stabilizers, namely , co-polymers, dendrimers, lipids, polymers, surfactants, and starch have been used to obtain fine and stable noble metal particles obtained by these methods [14,15]. Capping agents keep the nanoparticles away from agglomeration besides modifying their morphology as well. Especially, colloidal silver nanoparticles is of particular interest because of distinctive properties, such as good conductivity, chemical stability, catalytic and antibacterial activity [16-18]. Surfactants are amphiphilic molecules that create highly anisotropic interfacial regions lining the boundary formed by the highly polar aqueous and nonpolar hydrocarbon regions, imparting new chemical and physical properties to the system. Micelles, as well as other association colloids, can act as microreactors concentrating, separating, or diluting reactants, and thereby, they may have substantial effects on chemical reactivity [19]. Surfactants role in bulk solution and at interfaces is of great importance in surface chemistry. Surfactants properties have attracted growing attention for use in biological and chemical research applications. Because of their peculiar characteristics, various investigators used CTAB to synthesized multi-branched and/or multi-pods (monopods, bipods, tripods, and tetrapods) metallic nanoparticles. It has been recognized that, for the anisotropic morphology of silver and gold nanoparticles, CTAB is required as a shapedirecting agent [20-22].

Lee et al. [23] used the extract of unicellular green alga Chlorella vulgaris as reducing cum shape-directing agents and reported a biological to biomimetic chemical reduction method to the synthesis of single-crystalline gold and silver nanoplates. The alfalfa plants has been used for the formation of gold and silver nanoparticles by Jose-Yacaman and his co-workers for the first time [24]. Recently [25-27], we have reported the preparation of silver nanoparticles by using greener reducing and/or stabilizing agents in presence and absence of CTAB. It is believed that the use of biomolecules , especially green leaves and plants aqueous extract governed the morphology and plays an important role in the synthesis of advanced nanomaterials. This paper contributes first experimental evidence to the shape-directing and/or controlling role of $[\mathrm{CTAB}]$ and $\left[\mathrm{Ag}^{+}\right]$by using aqueous extract of Tulsi leaves extract at room temperature.

\section{Experimental and methods}

\subsection{Materials}

Silver nitrate $\left(\mathrm{AgNO}_{3}\right)$ and cetyltrimethylammonium bromide were purchased from Merck India ( $99 \%$ ) and used without further purification. Double distilled (first time from alkaline permanganate), deionized and ultra pure water was used as solvent for all aqueous preparations. All glassware was washed by ultrasonication in a mixture of ultrapure water and nonionic detergent and dried prior to use. Ocimum sanctum leaves collect from the campus of our University, thoroughly washed with tape water followed distilled water to remove dust particles and heated for 300 min with $250 \mathrm{~cm}^{3}$ distilled water in a $500-\mathrm{cm}^{3}$ Erlenmeyer flask. The mixture was cooled and filtered with Whatman paper No. 1. Filtrate was collected, stored at room temperature and used for the reduction of $\mathrm{AgNO}_{3}$.

\subsection{Preparation of nanoparticles}

A simple one step reaction of silver nitrate with leaves extract is used to prepare silver nanocolloid. In a typical experiment, required amount of leaf extract was added in a reaction mixture containing $\mathrm{AgNO}_{3}+\mathrm{H}_{2} \mathrm{O}$ (for dilution) and $\mathrm{AgNO}_{3}+\mathrm{CTAB}+\mathrm{H}_{2} \mathrm{O}$. As the reduction of $\mathrm{Ag}^{+}$to $\mathrm{Ag}^{0}$ occurs, the reaction mixture turns light brown, indicating the formation of silver nanoparticles in absence and presence of CTAB [23, 25]. The color of solutions obtained with various [CTAB] is slightly different.

\subsection{Morphology determination}

\section{UV-Vis Absorption spectrophotometer}

Absorption spectra of samples were recorded using UV-Vis spectrophotometer by VARIAN.

Transmission Electron Microscopy (TEM)

The morphology, dimensions of in situ synthesized silver nanoparticles in CTAB were studied using Transmission electron microscope (TEM, CM 20,CX Philips at 160kv) by putting a drop sample on a carbon coated copper grid.

\section{Results and Discussion}

\subsection{Morphology without stabilizer}

The color of colloidal silver is due to a phenomenon known as surface plasmon resonance. In silver nanoparticles the conduction band and valence band lie very close to each other in which electrons move freely. These free electrons give rise to a surface plasmon resonance absorption (SRP) band occurring due to the collective oscillation of electrons of silver nanoparticles in resonance with the light wave. The UV-Vis spectra of the silver nanoparticles prepared by using different $\left[\mathrm{Ag}^{+}\right]$(from 4.0 to $12.0 \times 10^{-4} \mathrm{~mol} \mathrm{dm}^{-3}$ at constant aqueous leaves extract are given in Fig. 1 . The all spectra show a shoulder at $450 \mathrm{~nm}$ for a short reaction time. As the reaction time increases sharpness of SRP band increases. This 
implies that $\left[\mathrm{Ag}^{+}\right]$has no significant effect on the nucleation and growth of silver nanoparticles. Only small concentrations of $\mathrm{Ag}+$ ions are sufficient to the nucleation process. Once the reactive species generated which acts as the catalyst to the reduction of other metal ions $[1,11]$. On the other hand, intensity of the band increases with time, indicating that the reaction time is an important parameter for the growth of silver nanoparticles. In order to see the role of leaves extract, a series of kinetic experiments were performed at fixed $\left[\mathrm{Ag}^{+}\right]\left(12.0 \times 10^{-4} \mathrm{~mol} \mathrm{dm}^{-3}\right)$ with leaves extract $\left(5.0 \mathrm{~cm}^{3}\right)$. Inspection of Fig. 2 clearly suggested that the intensity of SRP band decreased which might be due to the adsorption of leaves constituents onto the surface of silver nanoparticles. Visual observation showed that the color of silver nanoparticles changed from pale yellow, yellow, light-red to wine-red with reaction time. The digital images to the formation of silver nanoparticles as a function of time are given in Fig. 3 indicating that the appearance of color strongly depends on the reaction time.

TEM studies of the silver nanoparticles revealed irregular morphology of the particles in the size range $10 \mathrm{~nm}$ to $25 \mathrm{~nm}$ (Fig. 4). Particles were spherical as the main product of silver nanocrystals with some truncated triangular nanoplates having mean diameter of $15 \mathrm{~nm}$, indicating the reducing and shape directing role of the leaves constituents in the anisotropic growth of nanocrystals (Fig.4A). The nanoplates could be formed by the dissolution of the corner atoms of truncated triangular nanoplates.

\subsection{Morphology with stabilizer}

It has been accepted that the CTAB acted as a shape-directing agent during the growth of multi-branched metal nanoparticles [1,]. Tha appearance and/or change of color strongly depends on the [CTAB]. Therefore, the effect of [CTAB] was studied at constant $\mathrm{Ag}^{+}$and leaves extract concentrations and varying concentration of CTAB from 4.0 to 10.0 $\times 10^{-4} \mathrm{~mol} \mathrm{dm}^{-3}$. These results are summarized in Figs. $4(\mathrm{~B})$ and 5 as TEM images and absorbance-wavelength profiles as a function of time, respectively. Interestingly, initially different color observed but after some time, all reaction mixtures show the different color, which is due to the regular and uncontrolled aggregation. The change in the position of SRP band (red-shifting and broading), appearance of many bands (400, 475 and 600 nm; Fig. 5B) and a broad shoulder (Fig. 5C) with $[\mathrm{CTAB}]$ indicate that initially small nanoparticles grow to form larger particles having anisotropic morphology. In presence of CTAB, the resulting nanoparticles were poly-dispersed (Fig.4B). Some anisotropic nanostructures, such as nanotriangles or nanoparticles with irregular contours, could be observed in the TEM images. The coexistence of triangular and spherical particles indicate the presence of three absorbance at around 400, 475 and $600 \mathrm{~nm}$, which are in good agreement with the spectroscopic data ( two bands and a shoulder at ca. 400,450 and $600 \mathrm{~nm}$, respectively, might be due to the out-of-plane dipole- , transverse- and longitudinal-resonance of small spherical, faceted, anisotropic nanoparticles and nanorods formation in the system [28, 29]). Thus we may safely conclude that CTAB acts as a shapedirecting agent. The our observations and above explanations are in good agreement with results of various researches (Bakshi and his coworkers [30, 31], Mulvaney [32], Nikoobakht and El Sayed [12] ) to the shape-controlling role of normal and hydrophobic double tail Gemini surfactants.

In order to explain the actual role of CTAB, conductometric technique has been used to determine the critical micellar concentration (CMC) values of CTAB solutions at different experimental conditions, i.e., CTAB only, $\mathrm{CTAB}+\mathrm{AgNO} \mathrm{O}_{3}$, $\mathrm{CTAB}+$ leaves extract. The CMC values were determined from the reported method. The break point of nearly two straight-line portions in the plot is taken as an indication of micelle formation and this corresponds to the CMC of surfactant. The CMC values were found to be $9.9 \times 10^{-4}, 9.2 \times 10^{-4}$, and $8.9 \times 10^{-4} \mathrm{~mol} \mathrm{dm}^{-3}$ for water + CTAB, CTAB + $\mathrm{AgNO}_{3}\left(12.0 \times 10^{-4} \mathrm{~mol} \mathrm{dm}^{-3}\right)$, and CTAB + leaves extract $\left(5.0 \mathrm{~cm}^{3}\right)$ at room temperature. Inspection of Fig.5 clearly indicated that the CTAB has significant effect on the nucleation and SRP band position and shape markedly suppressed with increasing [CTAB], suggesting the adsorption of $\mathrm{Ag}^{0}$ on to the head group the CTAB. As a result, nanoparticles of different morphologies thus formed at different CTAB concentrations. The CMC is lower than in water, suggesting that the active species of reactants and product adsorbed and/or associates with positive head group of CTAB aggregates not only electrostatically but also coulombically and van der Walls forces. The observed pre-micellar effects on the growth of nanoparticles can be brought in fact that the small aggregates of CTAB (dimers, trimers, tetramers, etc ) exit below the CMC. The distribution of surfactant $\left(D_{1}\right)$ between various states of aggregation is controlled by a series of dynamic association-dissociation equilibria:

$$
\begin{array}{ll}
\mathrm{D}_{1}+\mathrm{D}_{1} \rightleftharpoons & \mathrm{D}_{2} \\
\mathrm{D}_{1}+\mathrm{D}_{2} \rightleftharpoons & \mathrm{D}_{3} \\
\mathrm{D}_{\mathrm{n}-1}+\mathrm{D}_{1} \rightleftharpoons & \mathrm{D}_{\mathrm{n}}
\end{array}
$$

The pre-micellar role of CTAB can be sought in the fact that small aggregates of the CTAB exist below the CMC, these submicellar aggregates would interact physically with the $\mathrm{Ag}^{0}$. The interaction and or adsorption of CTAB and growing metal particles play a significant role in this type of growth. At higher [CTAB], itt is interesting to note that there is a broad shoulder begins to develops in the whole visible region instead of a peak (Figs. 5C). The shape of the spectra entirely changed at higher [CTAB]. This is due to the incorporation and/or association of leaves constituents into the Stern layer of CTAB micelles. Possibility of $\mathrm{Ag}^{+}$ions incorporation in the micellar pseudo-phase cannot be ruled out because Stern layer are water rich. The observed aggregated and ordered morphologies with clear shapes suggests that the growth process of a nucleating center is fully controlled by an effective blocking of the fcc crystal planes by biomolecules [33, 34]. 


\section{Conclusions}

The in situ reduction of silver ions with leaves extract with and/or without CTAB has been reported. Our study clearly demonstrates that CTAB concentration plays a major role in determining the dimensions as well as the stability of the silver colloidal solution. The morphology are not only depends on the [CTAB], but also on the time. Pre- and postmicellization also plays an important role in the preparation of different colored silver sols. Our results suggest that the preparation of advanced nanomaterials having a range of optical properties might be achievable through careful control over the concentration of the stabilizer in solution.

\section{References}

[1] T.Pal, T. K. Sau, N. R. Jana, Langmuir 13 (1997)1481.

[2] M. A. El-Sayed, Acc. Chem. Res. 34 (2001) 257.

[3] A. Ahmad, P. Mukherjee, S. Senapati, D. Mandal, M. I. Khan, R. Kumar, M. Sastry, Colloids Surf B 28 (2003) 313.

[4] A. Sileikaite, I. Prosycevas, J. Puiso, A. Juraitis, A. Guobiene, Material science 12(2006)4.

[5] S. D. Solomon, M. Bahadory, A. V. Jeyarajasingam, S. A. Rutkowsky, C. Boritz, J Chem Education 84 (2007)2.

[6] V. K. Sharma, R. A. Yngard, Y. Lin, Adv. Colloid Interface Sci. 145 (2009) 83.

[7] T.C. Prathna, N. Chandrasekaran, A. M. Raichur, A. Mukherjee, Colloids Surfs B: Biointerfaces 82 (2011) 152

[8] Z. Khan, J. I. Hussain, A. A. Hashmi, Colloids Surfs, B: Biointerfaces 95 (2012) 229

[9] Z. Khan, T. Singh, J. I. Hussain, S. A. Al-Thabaiti, E. H. El-Mossalamy, A. Y.

Obaid, Colloids Surfs, B: Biointerfaces 102 (2013) 578.

[11] A. Henglein, J. Phys Chem 97 (1993) 5457.

[12] B. Nikoobakht, M. A. El-Sayed, Chem Mater 15 (2003) 1957.

[13] R. Pasricha, A. Singh, M. Sastry, J Colloid Interface Sci 333 (2009) 380.

[14] A. Henglein, Chem. Rev. 89 (1989)1861

[15] M.-P. Pileni, Nature Mate 2 (2003) 145.

[16] M. Harada, K. Saijo, N. Sakamoto, K. Ito, J. Colloid Interface Sci 343 (2010) 423.

[17] M. S. Bakshi, J. Nanoscience Nanotechnology 10(2010) 1757.

[18] P. Khullar, V. Singh, A. Mahal, P. N. Dave, S. Thakur, G. Kaur, J. Singh, S. S. Kamboj, M. S. Bakshi, J Phys Chem C 116 (2012) 8834.

[19] C. A. Bunton, G. Savelli, Adv Phys Org Chem 22 (1987) 213.

[20] T. K. Sau , C. J. Murphy, J Am Chem Soc 126 (2004) 8648.

[21] S. H. Chen, Z. L Wang, J. Ballato, S. H. Foulger, D. L. Carroll, J Am Chem Soc 125 ( 2003) 16186.

[22] M. S. Bakshi, Langmuir 25 (2009) 12697.

[23] J. Xie, J. Y. Lee, D. I. C. Wang, Y. P. Ting, ACS Nano 1 (2007) 429.

[24] J. L. Gardea-Torresdey, E. Gomez, J. Peralta-Videa, J .G .Parsons, H. Troiani, M. Jose-Yacaman, Langmuir 19 (2003) 1357

[25] Z. Zaheer, Rafiuddin, Colloids Surfaces B: Biointerfaces 108 (2013) 90.

[26] Z. Zaheer, Rafiuddin, J. Experimental Nanoscience 7 (2012) 366.

[27] Z. Zaheer, Rafiuddin, Int. J. Chem. Kinet. 44 (2012) 680.

[28] R. C. Jin, Y. W. Cho, C. A. Markin, K. L. Kelly, G. C. Schatz, J. G. Zheng, Science, 294 (2001) 1901.

[29] Z. Khan, S. A. AL-Thabaiti, A. Y. Obaid, Z. A. Khan, A. O. Al-Youbi, J. Colloid Interface Sci. 367 (2012) 101.

[30] M. S. Bakshi, P. Thakur, G. Kaur, H. Kaur, T. S. Banipal, F. Possmayer, N. O. Petersen, Adv Funct Mater 19( 2009) 1451.

[31] M. S. Bakshi, J Phys Chem C 115 (2011) 13947.

[32] P. Mulvaney, Langmuir 12 (1996)788. 
[33] K. Murayama, K. Tomida, Biochemistry 43 (2004) 11526.

[34] M. S. Bakshi, F. Possmayer, N. O. Petersen, J Phys Chem C 111 (2007) 14113.

\section{Figure captions}

Fig.1. Effects of $\left[\mathrm{Ag}^{+}\right]$on the shape and position of silver nanoparticles spectra prepared by the reduction of $\mathrm{Ag}^{+}$ions $(4.0$ (A), 8.0 (B) and $\left.12.0 \times 10^{-4} \mathrm{~mol} \mathrm{dm}^{-3}(\mathrm{C})\right)$ with leaves extract $\left(10.0 \mathrm{~cm}^{3}\right)$.

Fig.2. Effects of [extract] on the shape and position of silver nanoparticles spectra prepared by the reduction of $\mathrm{Ag}^{+}$ions $\left(12.0 \times 10^{-4} \mathrm{~mol} \mathrm{dm}^{-3}\right)$ with leaves extract $\left(15.0 \mathrm{~cm}^{3}\right)$.

Fig.3. Photographs showing the effect of time on the variation of color to the formation of silver nanoparticles by the reduction of $\mathrm{Ag}^{+}$ions $\left(12.0 \times 10^{-4} \mathrm{~mol} \mathrm{dm}^{-3}\right)$ with leaves extract $\left(10.0 \mathrm{~cm}^{3}\right)$.

Fig. 4. TEM images of silver nanoparticles formation by the reduction of $\mathrm{Ag}^{+}$ions $\left(12.0 \times 10^{-4} \mathrm{~mol} \mathrm{dm}^{-3}\right)$ with leaves extract $\left(10.0 \mathrm{~cm}^{3}\right)$ in absence $(A)$ and presence of $(B)$ of CTAB $\left(10.0 \times 10^{-4} \mathrm{~mol} \mathrm{dm}^{-3}\right)$.

Fig.5. Effects of $[C T A B]$ on the shape and position of silver nanoparticles spectra prepared by the reduction of $\mathrm{Ag}^{+}$ions $12.0 \times 10^{-4} \mathrm{~mol} \mathrm{dm}^{-3}$ ) with leaves extract $\left(10.0 \mathrm{~cm}^{3}\right.$ ) in presence of CTAB (from $6.0(A), 8.0(B)$ and $10.0 \times 10^{-4} \mathrm{~mol} \mathrm{dm}^{-3}$ $(\mathrm{C})$ ).

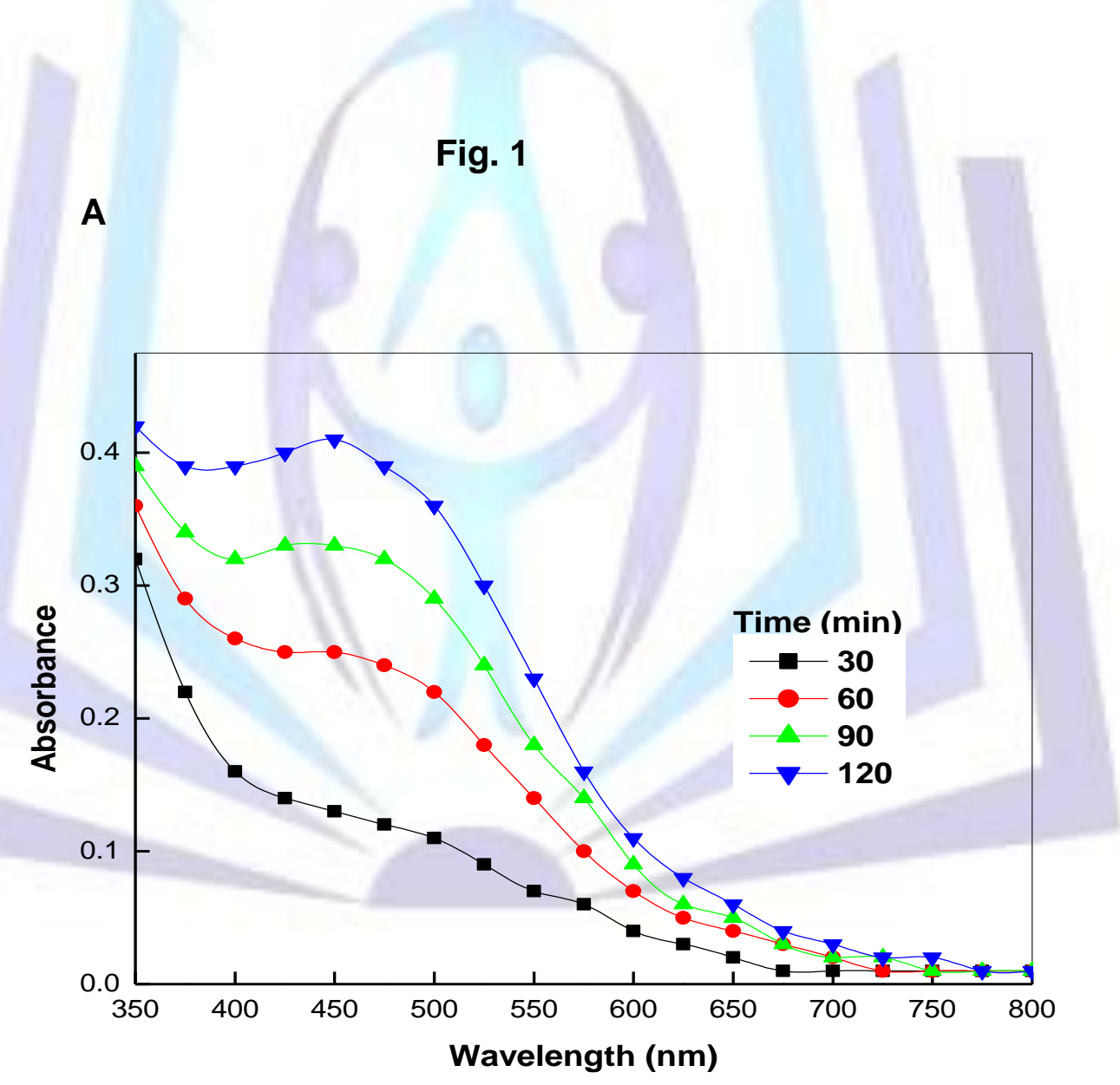




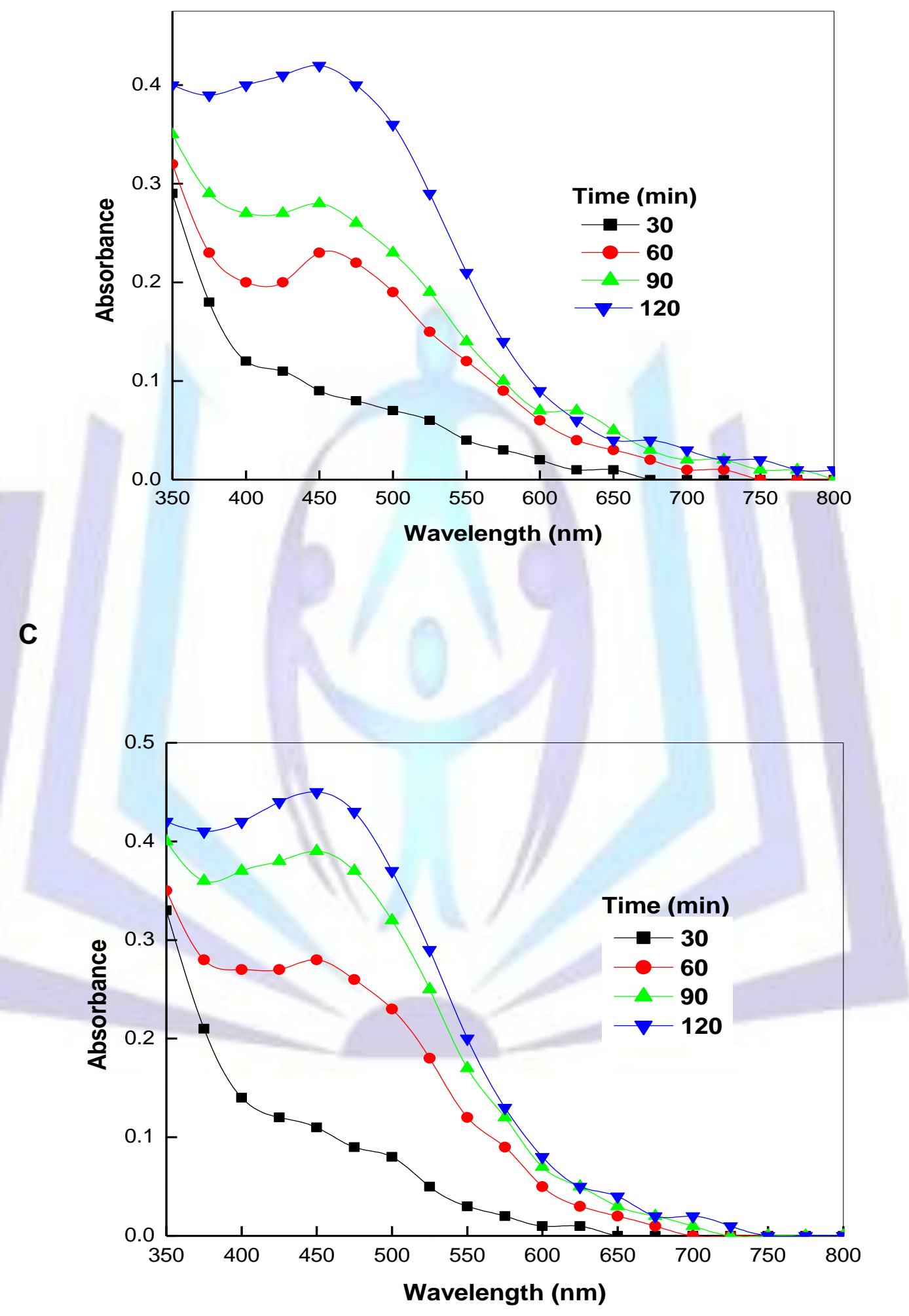


Fig. 2

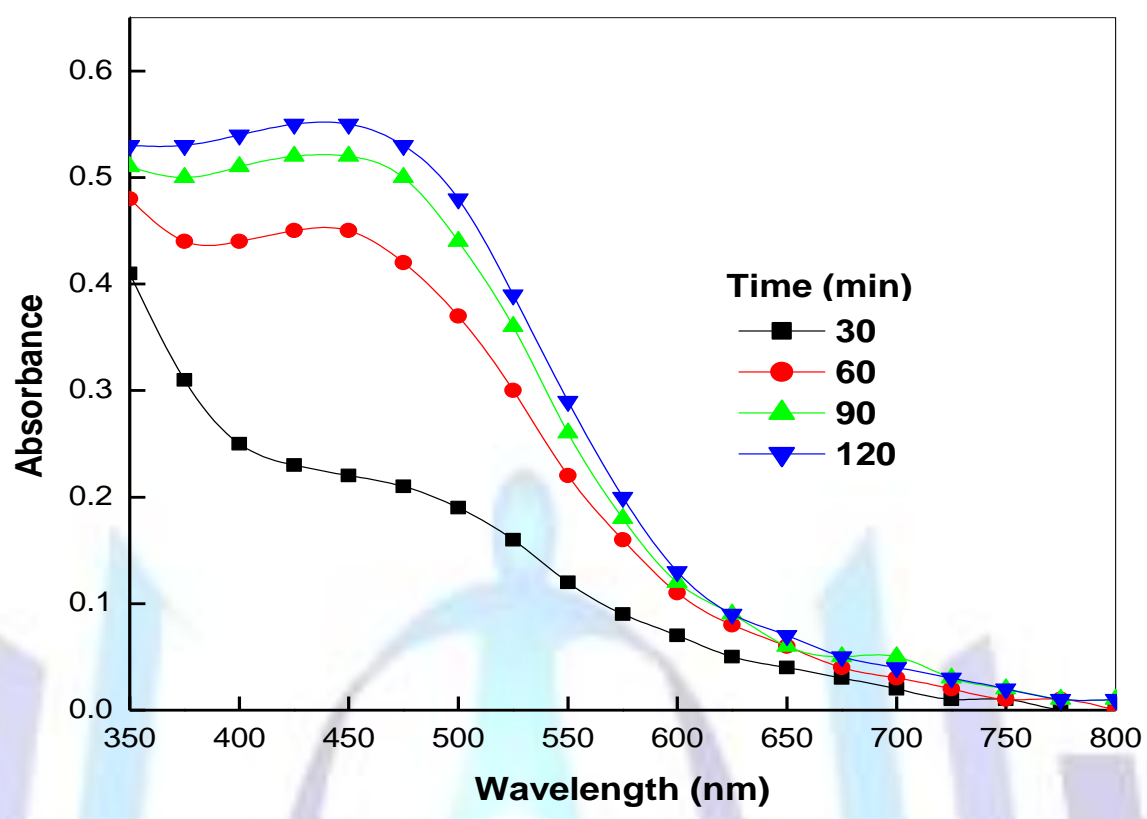

Fig.3

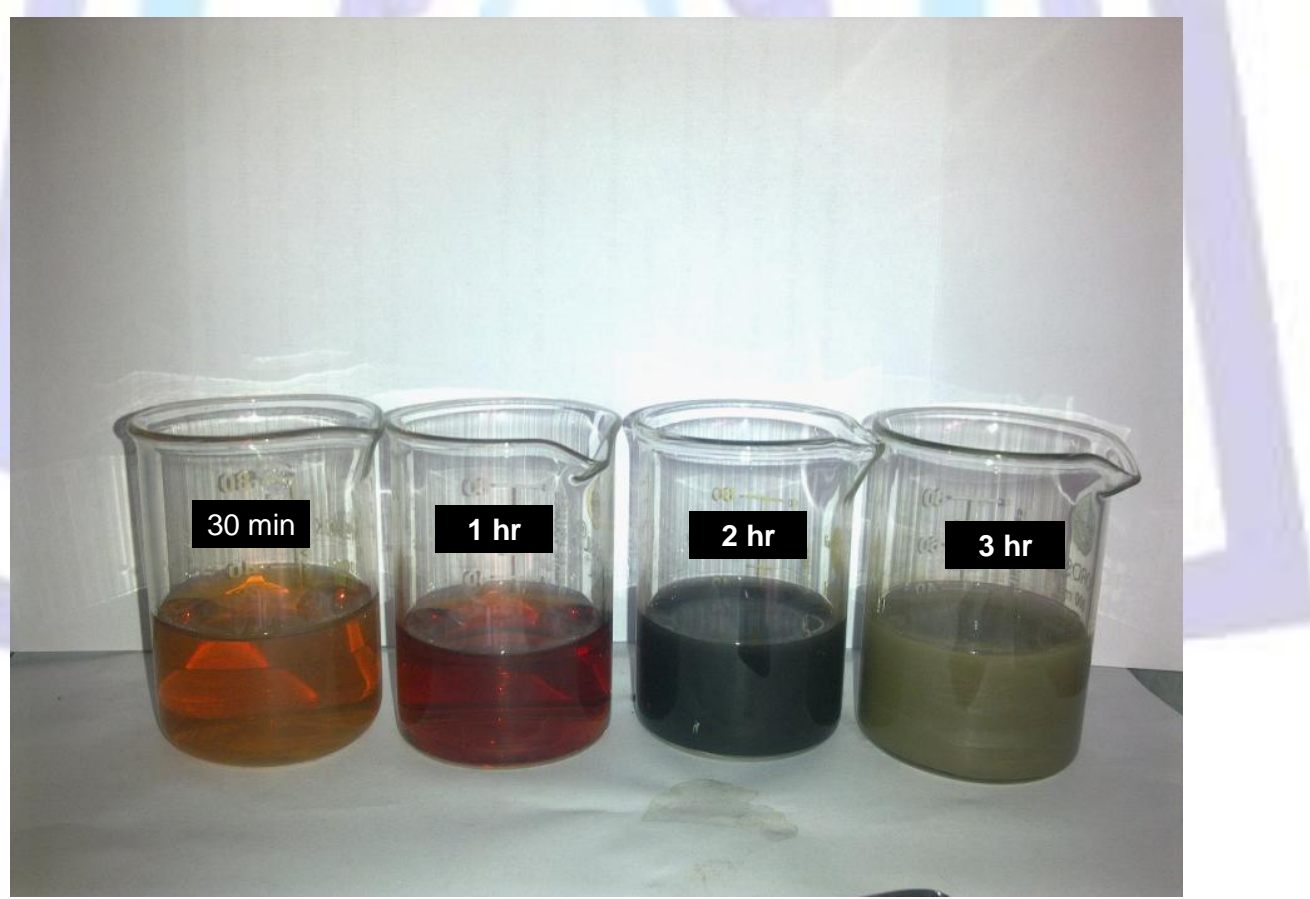


Fig. 4

A

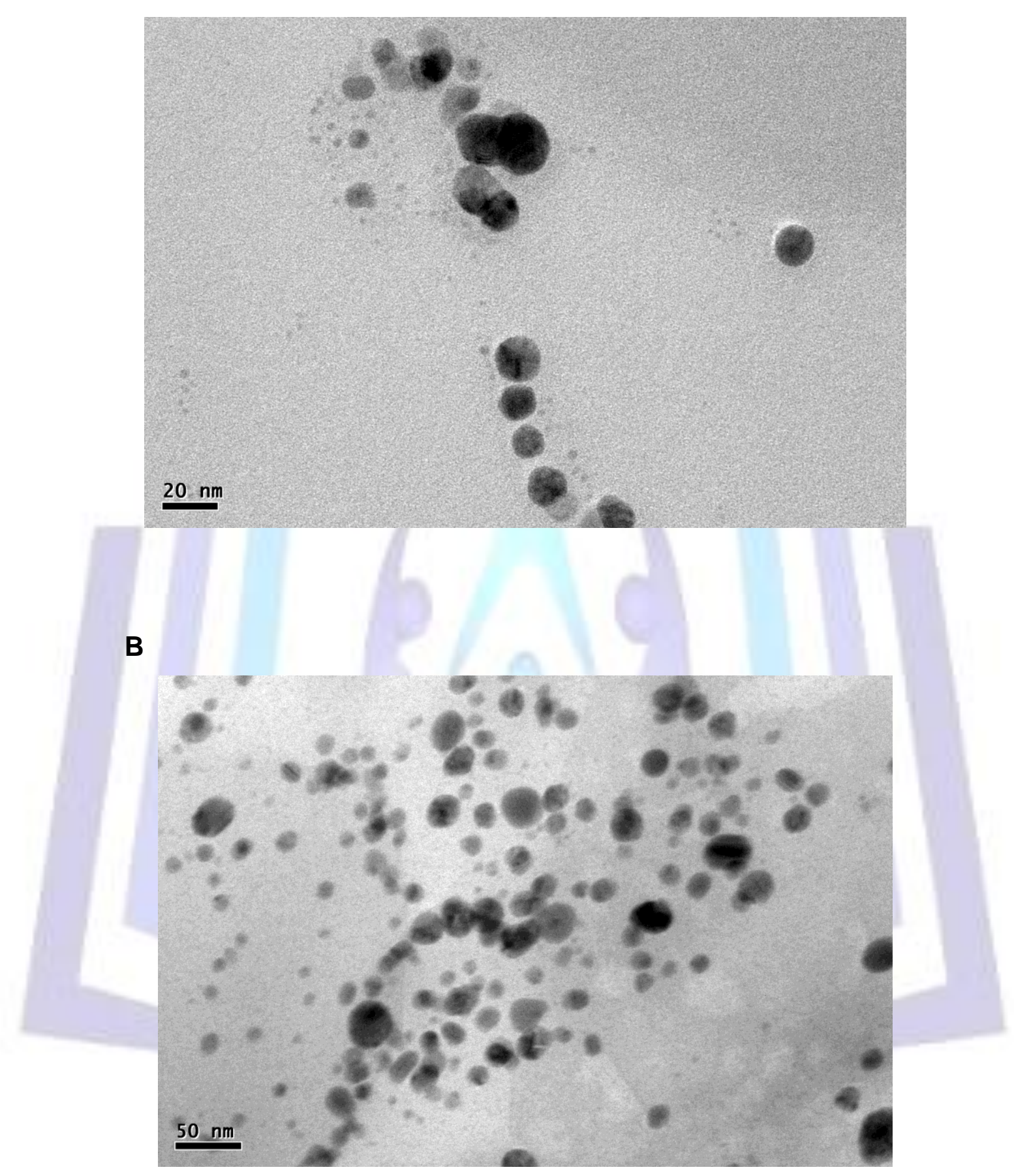


Fig.5

A

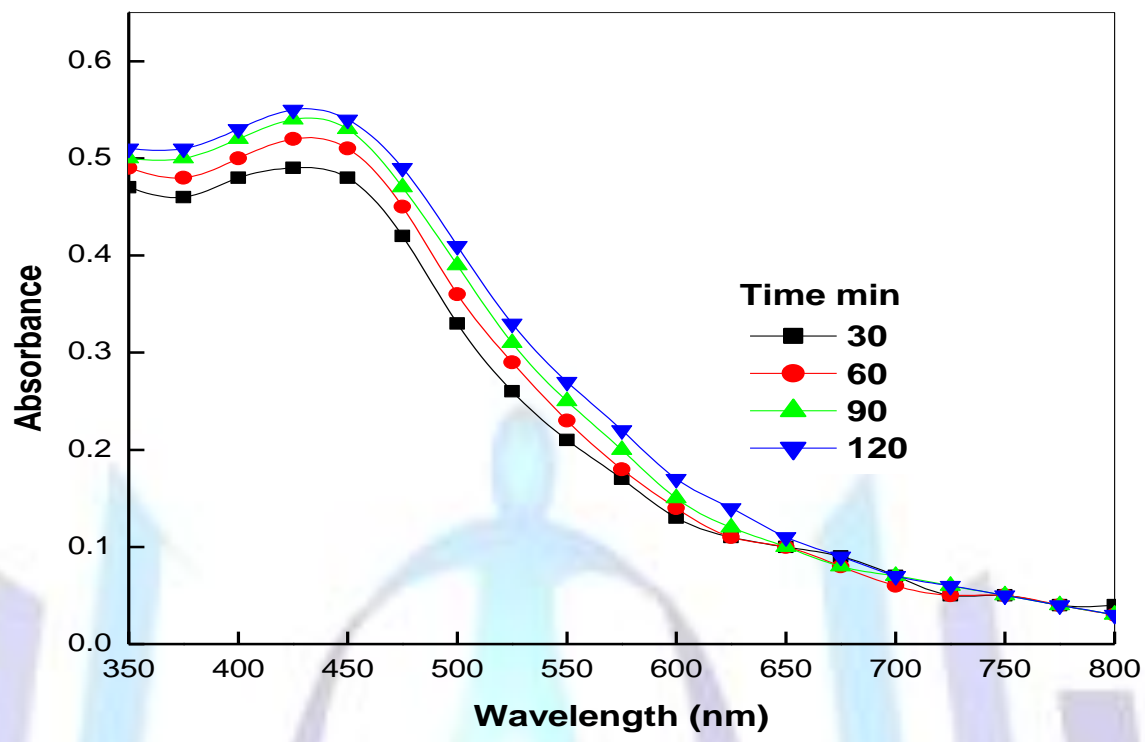

B

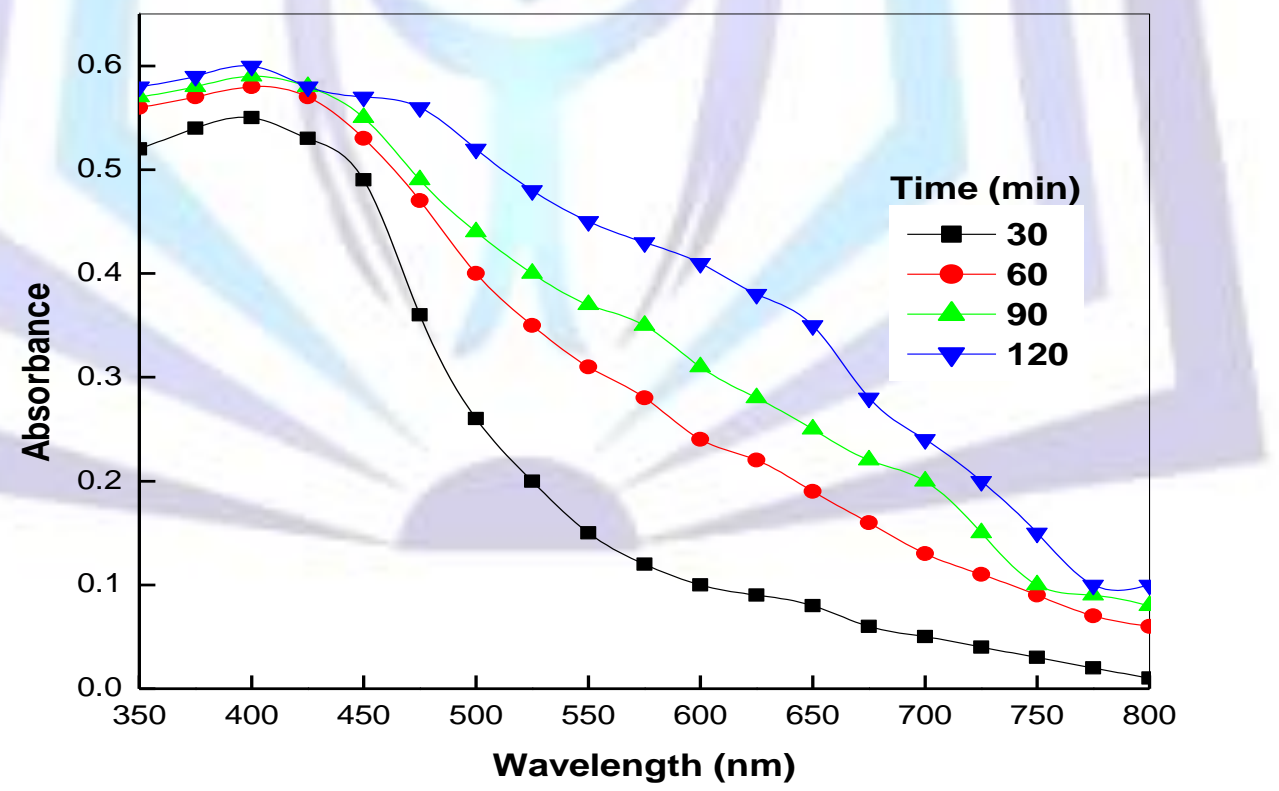


C

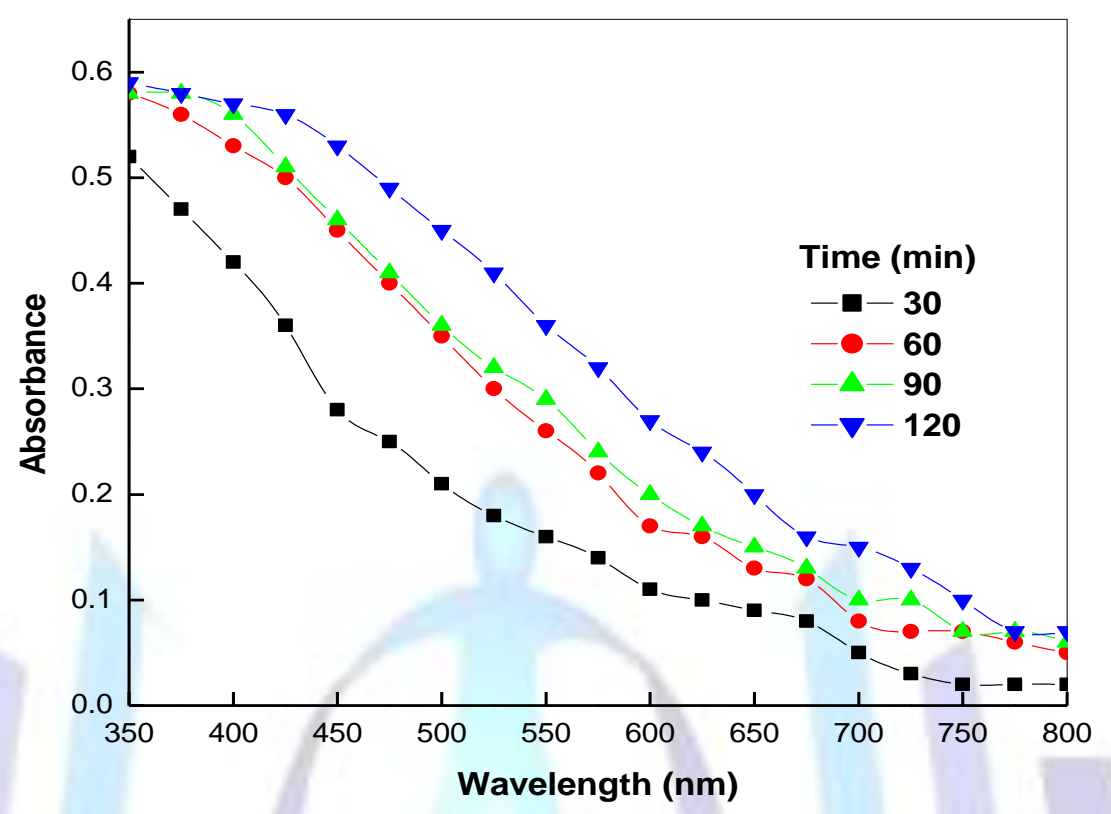

